\title{
Electrochemical and bioelectrocatalytical properties of novel block-copolymers containing interacting ferrocenyl units
}

\author{
M.P. García Armada ${ }^{\text {a }, *}$, J. Losada a , F.J. López-Villanueva ${ }^{b}$, H. Frey ${ }^{b}$, B. Alonso ${ }^{c}$, C.M. Casado ${ }^{c}$ \\ apto. de ingeniería Química industrial, E.T.S.I.,. U.P.M., José Gutiérrez Abascal no. 2, 28006 Madrid, Spain \\ 'Institute of Organic Chemistry, Organic and Macromolecular Chemistry. Duesbergweg 10-14, Johannes Gutenberg-Universität Mainz, D-55099 Mainz, Germany \\ 'Dpto. de Quimica inorgánica, Facultad de Ciencias, U.A.M., Cantobianco, 28049 Madrid, Spain
}

\section{A R T I C L E I N F O}

\section{Article histony:}

Received 14 March 2008

Received in revised form 28 May 2008

Accepted 28 May 2008

Available online 4 June 2008

\section{Keywords:}

Bielectronic oxidation

Electronic communication

Ferrocene

Organometallic block-copolymers

NADH

$\mathrm{GOX}$

\begin{abstract}
A B S T R A C T
The electrochemical characterization of three different polystyrene-b-polybutadiene block-copolymers, functionalized with diferrocenylsilane units, is reported. The PB-blocks have been functionalized with different fractions of electronically communicated, $\mathrm{PS}_{n-}-\mathrm{PB}_{n},\left(\mathrm{HSiMeFc}_{2}\right)_{p}$ units, where $n=615$, $n=53, p=39(1), m=375, n=92, p=76$ (2) and $n=455, n=204, p=170$ (3). Electrochemical characterization has been carried out both in solution and after electrochemical deposition onto platinum electrodes. The bioelectrocatalytical properties of electrodes modified with the polymers in the nicotinamide dinucleotide (NADH) and glucose oxidase (GOx) oxidations have been investigated as a function of the constitution and structure of the polymers. The analytical properties of electrodes modified with these polymers as sensors of $\mathrm{NADH}$ and GOx are described. In addition, an amperometric biosensor for glucose, prepared by electrostatic immobilization of glucose oxidase onto a platinum electrode modified with one of the ferrocenyl block-copolymers as an example, has been developed.
\end{abstract}

\section{Introduction}

Incorporation of organometallic groups into polymeric structures leads to materials with unusual and attractive characteristics. New materials with interesting properties for various fields such as electrochemistry, materials science, organic synthesis and catalysis have been reported $[1,2]$. The excellent thermal and photochemical stability as well as the unique and valuable redox properties of ferrocenes are well known, and in recent years a large number of research groups have investigated various polymer systems with ferrocenyl-containing structures. Different topologies have been developed, containing the ferrocene moieties as part of the backbone or as side group of a linear chain $[3,4]$. Research in this direction has also been motivated by advances in the field of dendrimer synthesis and this has led to the development of different examples of ferrocene-functionalized dendrimers $[5,6]$.

Block-copolymers may form supramolecular structures and can also be used to create micropatterned surfaces. In solution they form micellar aggregates that can represent a special environment for electrochemistry. This renders them very interesting in this field of science, and therefore the development of ferrocenyl-con- taining block-copolymers has become an important issue [7-10]. The corresponding methods developed by Nuyken et al. and Frey et al. are based on the controlled anionic and radical polymerization, respectively, and were successfully applied for the copolymerization of vinylferrocene with styrene or other olefinic monomers [11,12]. Balsara et al. showed that a poly(vinylferrocene)-b-poly(isoprene) block-copolymer can be successfully applied as heterogeneous catalyst for Michael additions [13]. Intensive research performed by Manners has led to a wide range of examples concerning block-copolymers with a well-defined ferrocene-containing block [14].

Amperometric enzyme electrodes combine the specificity and selectivity of biological molecules with the direct transduction of reaction rate into current response and represent powerful tools in the field of analysis and biotechnology. Poly(ferrocenyl)-based macromolecules have been demonstrated to possess useful properties for the chemical modification of electrodes and also as electrochemical sensors and electrode mediators in biosensors [15-19].

In biosensoric applications polymers containing ferroceny] groups are combined with enzymes for use in aqueous media. Generally in enzymes the cofactor is buried within the enzyme structure that forms an insulating layer between an electrode and the redox-cofactor of the enzyme bound to the electrode surface. Using a mediator between electrode and enzyme may represent a possjbility to increase the sensibility in biosensors. Particularly ferrocenes have been proven to be very useful in this regard, because 
of their favorable formal potential with respect to enzyme redox chemistry. Unfortunately, the oxidized ferricinium species is soluble in aqueous media, which leads to undesired dissolution of the film. In the current work, the hydrophobic nature of polystyrene (PS) as one block in block-copolymers consisting of PS and a polybutadiene block modified with ferrocene units, can impede solubjlization of even very ferrocene-rich polymer films after oxidation.

Flavin-dependent oxidases and nicotinamide adenine dinucleotide (NAD/NADH) dependent dehydrogenases have been investigated for a long time because of their important role in many biochemical reactions.

$\mathrm{NAD} / \mathrm{NADH}$ dependent dehydrogenases need the freely diffusing cofactor $\mathrm{NAD}^{+}$to catalyze oxidation of the substrates. The major problem in practical applications of dehydrogenases is the difficulty in the regeneration of the nicotinamide coenzyme. Electro-oxidation of NADH on solid electrodes usually requires high potentials. A large number of redox mediators such a quinones, phenazines or inorganic molecules can be used to shuttle the electrons from NADH to the electrode in order to reduce the overpotential [20-22]. Another approach is the use of suitable electrodes modified with appropriate mediators [23]. A good method to accelerate the NADH oxidation is the use of the diaphorase reaction coupled with an electron mediator as ferrocene and its derivatives [24].

Mechanistic studies have been made on NADH or model compounds and it has been discussed whether the reaction is a twoelectron transfer or involves two single-electron transfers. It has been shown that generally mediators of the two-electron-proton acceptor type in contrast to the one-electron non-proton type present high second-order rate constants with NADH and yield enzymatically active $\mathrm{NAD}^{+}$as the reaction product [25]. Flavindependent oxidases containing tightly bound FAD in the active center of the enzyme can be electrochemically oxidized by electrodes through mediation by redox mediators. Long-range electron transfer to active sites of these enzymes has been demonstrated. both with enzymes in solution and co-immobilized in two- and three-dimensional surface polymer structures [26]. Several authors have reported that polymers and dendrimers functionalized with ferrocene groups can effectively mediate the electron transfer to glucose oxidase [27-29].

Since $\mathrm{FAD} / \mathrm{FADH}_{2}$ is a two-electron redox couple and the ferrocene/ferricinium a one-electron couple two one-reduction steps are involved in the electrochemical reoxidation of the reduced enzyme redox center $\left(\mathrm{FADH}_{2}\right)$.

In the last years we have reported on the synthesis, redox behaviour and electrocatalytic properties of ferrocene-based materials containing dendritic building blocks with interacting ferrocenyl moieties grafted to multifunctional poly(methyl) siloxane backbones. As can be seen in these articles the electrocatalytic activity of these polynuclear organometallic compounds is favoured by the electronic communication and the short distance between adjacent ferrocenyl moieties within the polymer film $[16,17]$. The suitable distance between metallic centers allows simultaneous or quasi-simultaneous charge transfers to the enzymatic redox sites, decreasing the high overpotentials required for the electrochemical oxidation of the enzymes.

In this study we report an electrochemical study of anionically prepared diblock-copolymers and the use of platinum electrodes modified with them for the electrocatalytic oxidation of NADH and glucose oxidase. The copolymers consist of a 1,2-polybutadiene block (PB) with di(ferrocenyl)silane side groups as electroactive part and a polystyrene (PS) block that is intended to impart additional polymer properties, such as good solubility, film-forming properties and film-stability over multiple redox cycles. The degree of polymerization of both blocks, the polystyrene block as well as the ferrocene-bearing PB-block has been varied by anjonic polymerization and varying fractions of diferrocenylsilanes have been attached.

\section{Experimental}

\subsection{Chemicals and materials}

Karstedt's catalyst in xylene (2.1-2.4\% Pt) was purchased from $\mathrm{ABCR} \mathrm{GmbH} \& \mathrm{Co}$. KG and used as received. $\mathrm{PS}_{x}-\mathfrak{b}-\mathrm{PB}_{y}$ with a $100 \% 1,2-\mathrm{PB}$ content was prepared in $20 \mathrm{~g}$ amounts via a simplified anionic polymerization procedure [30], using a specially constructed reactor system suitable for working under high vacuum and pressure. Methanol, dichloromethane and other solvents and reagents were purchased from Acros and used as received or dried as described in the literature. tert-Butyllithium was purchased from Acros (1.5 M solution in pentane). B-Nicotinamide adenine dinucleotide (NADH), reduced dipotassium salt, glucose oxidase (GOX) from Aspergilus niger (type VII, $221000 \mathrm{U} / \mathrm{g}$ ), and glucose were supplied from Sigma. Glucose solutions were allowed to reach mutarotational equilibrium at room temperature for $24 \mathrm{~h}$ before use. All other chemicals were analytical grade and were used without further purification. Ultrapure water was used for preparation of the buffers, standards and electrochemistry work.

\subsection{Diferrocenyimethylsilane}

Ferrocenyllithium was generated in situ via the reaction of ferrocene $(4.4 \mathrm{~g}, 24 \mathrm{mmol})$ with $20 \mathrm{mmol}$ of $t-\mathrm{BuLj}$ in a mixture of $15 \mathrm{~mL}$ dried THF and $15 \mathrm{~mL}$ dried pentane at $0^{\circ} \mathrm{C}$, under an inert atmosphere. After stirring the mixture at this temperature for $30 \mathrm{~min}$, the temperature was lowered to $-30^{\circ} \mathrm{C}$ and $1.66 \mathrm{~g}$ (14.4 mmol) of dichloromethylsilane was added dropwise. After complete addition the reactants were sticred for $30 \mathrm{~min}$ at $-30^{\circ} \mathrm{C}$. The mixture was allowed to slowly warm to room temperature. Solvents were removed under vacuum, the crude product was dissolved in pentane and $\mathrm{LiCl}$ was removed by filtration. Solvent removal yielded an orange solid which was purified by flash chromatography over silica gel using a mixture of petrol ether and dichloromethane (10:1). After purification the product was obtained as dark orange crystals in $39 \%$ yield [31].

\subsubsection{Functionalization of $P S_{x}-b-P B_{y}$}

All catalytic reactions were conducted in parallel using Radley's 12-placed reaction carousel under inert gas $\left(\mathrm{N}_{2}\right)$. Two hundred milligrams of block-copolymer and an equimolar amount of diferrocenylmethylsilane according to the double bonds were dissolved in $5 \mathrm{~mL}$ of dried toluene and heated to $100^{\circ} \mathrm{C}$. Fifty microlitres Karstedt's catalyst was added and the mixture was stirred at $100^{\circ} \mathrm{C}$ for 3 days. The polymer was purified by repeated precipitation from THF/methanol $(5 \times)$. Vields obtained were in the range of 60-80\%. Typical ${ }^{1} \mathrm{H}$ NMR data $\left(\mathrm{CDCl}_{3}\right) \delta: 7.48-6.22\left(\mathrm{C}_{6} \mathrm{H}_{5}\right), 4.49-$ $3.93\left(\mathrm{C}_{5} \mathrm{H}_{5}, \mathrm{C}_{5} \mathrm{H}_{4}\right), 2.40-0.41\left(\mathrm{CH}_{2}\right), 0.23\left(\mathrm{~s}, \mathrm{CH}_{3}\right)$. Detailed synthesis, complete characterization and electrochemical studies will be published elsewhere [31,32].

\subsection{Apporatus}

Electrochemical measurements were performed using an Ecochemie BV Autolab PGSTAT 12. The experiments were carried out in a conventional three-electrode cell at $20-21^{\circ} \mathrm{C}$ with a Pt disk of $3 \mathrm{~mm}$ diameter as working electrode, a Pt wire as auxiliary electrode, and a BAS non-aqueous $\mathrm{Ag} / \mathrm{Ag}^{+}$reference electrode or a saturated Calomel reference electrode (SCE) were employed in organic solvents or in aqueous media respectively. In steady-state measurements, an Autolab rotating-disk electrode was used and 
the amperometric measurements were performed in $0.1 \mathrm{M}$ phosphate buffer with $0.1 \mathrm{M} \mathrm{NaClO}_{4}$ deoxygenated by bubbling highpurity nitrogen. The background current was allowed to decay to a steady value before aliquots of stock NADH or glucose solution were added.

${ }^{1} \mathrm{H}$ nuclear magnetic resonance (NMR) spectra were recorded at a frequency of $300 \mathrm{MHz}$ using a Bruker $\mathrm{AC} 300$ or on a Bruker $\mathrm{AMX}$ 400 working at $400 \mathrm{MHz}$ using deuterated chloroform as solvent.

Size exclusion chromatography (SEC) was performed on an instrument consisting of a Waters 717 plus autosampler, a TSP Spectra Series P 100 pump and a set of three PSS-SDV $5 \mu \mathrm{m}$ columns with 100,1000 , and $10000 \AA$ porosity. THF was used as an eluent at $30^{\circ} \mathrm{C}$ and at a flow rate of $1 \mathrm{~mL} \mathrm{~min}^{-1}$. UV absorptions were studied by a SpectraSYSTEM UV2000. The specific refractive index increment $(\mathrm{dn} / \mathrm{d} c)$ was measured at $30^{\circ} \mathrm{C}$ on an Optilab DSP interferometric refractometer (also RJ detector) and determined with the WYATT ASTRA IV software (Version 4.90.08).

\subsection{Electrode preparation}

The Pt disk electrode was polished using $0.1 \mu \mathrm{m}$ alumina powder and rinsed with water in an ultrasonic bath. The electrode surface was then conditioned by cycling the potential between the limits for hydrogen and oxygen evolution in $0.5 \mathrm{M} \mathrm{H}_{2} \mathrm{SO}_{4}$ solution until well-defined cyclic voltammograms were obtained, and then rinsed with water.

Films of the corresponding ferrocenyl-functionalized polymers (1, 2 and 3) were deposited on the above prepared surface from the electrolyte bath containing $1 \mathrm{mM}$ in the redox active species (ferrocene) and $0.1 \mathrm{M}$ tetrabutylammonium hexafluorophosphate in dichloromethane, which was deaerated with nitrogen prior to electrooxidation, under potentiostatic control at a potential of $+0.8 \mathrm{~V}$ (vs. $\mathrm{Ag} / \mathrm{Ag}^{+}$reference electrode). The coated electrodes were rinsed with dichloromethane.

The surface coverage of electroactive ferrocenyl sites in the films, $\Gamma$, was determined from the integrated charge of the cyclic voltammetric waves.

The polymer-modified electrodes were stored in ultrapure water at room temperature when not in use. The immobilization of the enzyme was carried out by immersing the polymer coated electrode in an electrochemical cell containing an enzyme solution ( $0.1 \%$ of $\mathrm{GOx}$ in acetate buffer, $\mathrm{pH} 5.3$, and $\mathrm{NaClO}_{4} 0.1 \mathrm{M}$ ). $\mathrm{A}+0.7 \mathrm{~V}$ vs. SCE potential was applied to the polymer coated electrodes during $30 \mathrm{~min}$ under stirring and nitrogen bubbling, subsequently the electrodes had been kept for $10 \mathrm{~min}$ in glutaraldehyde vapour at room temperature. The $\mathrm{pH}$ of the enzyme solution was kept at a value of 5.3 where the enzyme exists in the form of an anion, $\mathrm{GOx}^{\mathrm{m}-}$, facilitating its interaction with the oxidized copolymer. The prepared enzyme electrode was allowed to diy in air, and rinsed thoroughly with the buffer. The enzyme electrodes were stored in ultrapure water at $4{ }^{\circ} \mathrm{C}$ when not in use.

\section{Results}

\subsection{Synthesis of ferrocenyl-functionalized block-copolymers}

Three different block-copolymers with different fractions of styrene and butadiene units $(10: 1,4: 1$ and $2: 1)$ were prepared by anionic polymerization and subsequently functionalized at the PBblock with diferrocenylmethylsilane via hydrosilylation reaction. All block-copolymers 1a-3a prepared and the respective ferrocene-functionalized materials 1-3 are listed in Table 1 . For the hydrosilylation step, Karstedt's catalyst was employed, resulting in the organometallic block-copolymers $\mathrm{PS}_{1 n}-\mathrm{PB}_{n-p}\left(\mathrm{HSiMeFc}_{2}\right)_{\mathrm{p}}$ where $m=615, n=53, p=39$ (1), $m=375, n=92, p=76$ (2) and
Table 1

SECJMALLS/viscosimetry data of ferrocenyl-functionalized block-copolymers

\begin{tabular}{|c|c|c|c|c|}
\hline \multicolumn{2}{|c|}{ Compound } & \multirow{2}{*}{$\begin{array}{l}\text { Molar mass, } \\
M_{\mathbf{n}}{ }^{a}\left(\times 10^{-3} \mathrm{gmol}^{-1}\right) \\
66.9\end{array}$} & \multirow{2}{*}{$\begin{array}{l}\mathrm{PD}^{\mathrm{a}} \\
1.02\end{array}$} & \multirow{2}{*}{$\begin{array}{l}\text { Viscometric radius, } \\
\boldsymbol{R}_{\eta^{\mathrm{b}}}(\mathrm{nm}) \\
62\end{array}$} \\
\hline $1 \mathbf{a}$ & $\mathrm{PS}_{615}-\mathrm{PB}_{53}$ & & & \\
\hline 1 & $\mathrm{PS}_{615}-\mathrm{PB}_{53}\left(\mathrm{HSiMeF} c_{2}\right)_{39}$ & 98.6 & 1.04 & 6.6 \\
\hline $2 \mathbf{a}$ & $\mathrm{PS}_{375}-\mathrm{PB}_{92}$ & 44.1 & 1.07 & 5.1 \\
\hline 2 & $\mathrm{PS}_{375}-\mathrm{PB}_{92}\left(\mathrm{HSiMeFc_{2 }}\right)_{76}$ & 97.4 & 1.11 & 5.5 \\
\hline 3a & $\mathrm{PS}_{455}-\mathrm{PB}_{204}$ & 58.4 & 1.02 & 5.7 \\
\hline 3 & $\begin{array}{l}\mathrm{PS}_{455}-\mathrm{PB}_{304} \\
\left(\mathrm{HSiMeFc_{2 }}\right)_{170}\end{array}$ & 157.0 & 1.10 & 6.5 \\
\hline
\end{tabular}

- Determined via coupled SEC/MALLS.

- Molecular weight calculated from SEC with online viscosimetry.

$m=455, n=204, p=170$ (3) (Scheme 1 ). Detailed structural analysis of the block-copolymers was achieved by a combination of SEC with multi-angle light-scattering detector and NMR-spectroscopy [32]. SEC chromatograms measured in THF demonstrate a smal] shift of the peak maximum to lower elution volumes, as expected. According to SEC, all block-copolymers exhibited narrow polydispersity index ( $\mathrm{PD} I$ ) in the range of 1.02-1.11 after ferrocene functionalization of the PB-block (Table 1), which translates to very well-defined polymer structures.

${ }^{1} \mathrm{H}$ NMR spectra of the ferrocenyl-containing copolymers combine the signals typical for the PS block (between 6.3 and $7.3 \mathrm{ppm}$ the aromatic protons and between 0.8 and $2.4 \mathrm{ppm}$ the backbone protons are observed [32]), with the pattern of resonances in the cyclopentadienyl region characteristic of the newly introduced monosubstituted ferrocenes (between 4.00 and $4.40 \mathrm{ppm}$ ) and the methylsilyl singlet at $0.23 \mathrm{ppm}$. Firm evidence for the diferrocenylsilane functionalization was provided by the almost complete disappearance of the olefinic protons of the PBblock at 5.45 and $\mathbf{4 . 9 4} \mathrm{ppm}$. Based on the signals intensities the ferrocene fractions were estimated to be in the range of 10 to nearly $50 \mathrm{wt} \%$ of ferrocene. This corresponds to a degree of functionalization of $73-83 \%$.

\subsection{Electrochemical behaviour of the copolymers}

Cyclic voltammograms of the block-copolymers at low concentrations $\left(\sim 10^{-4} \mathrm{M}\right.$ in ferrocene centers $)$ in $\mathrm{CH}_{2} \mathrm{Cl}_{2}$ solutions exhibit two well-separated and reversible oxidation systems of equal intensity (Fig. 1).

This two-wave redox response is similar to that observed for oligo- and poly(ferrocenylsilanes) reported by Manners and coworkers [2] and polysiloxanes functionalized with diferroceny]methylvinylsilanes [33]. This electrochemical behaviour is consistent with the existence of appreciable interactions between the two iron centers bridged by a silicon atom. The initial oxidation occurs at non-adjacent ferrocene sites, which makes the subsequent removal of electrons from the remaining ferrocenyl centers, adjacent to those already oxidized more difficult.

In Fig. 1 it can be observed that the $\Delta E_{p}$ values of the cyclovoltammograms of the polymers obtained at a glassy carbon electrodes increase with increasing scan rates.

The corresponding standard rate constants for heterogeneous electron transfer $\left(k^{0}\right)$ of the first electron step are given in Table 2 , as estimated by the Nicholson's method [34], using the diffusion coefficients obtained from dynamic light scattering (DLS) [30]. It was also possible to determine the $k^{0}$ values for 1 and 2 by the application of the method of Milkin and Bard [35], employing rotating-disk electrode. The $\mathrm{k}^{0}$ values determined in this way were $1.29 \times 10^{-2} \mathrm{~cm} \mathrm{~s}^{-1}$ and $0.62 \times 10^{-2} \mathrm{~cm} \mathrm{~s}^{-1}$ for 1 and 2 , respectively. All values obtained are comparable to standard rate constants for other reported macromolecules containing ferrocene groups [36]. 


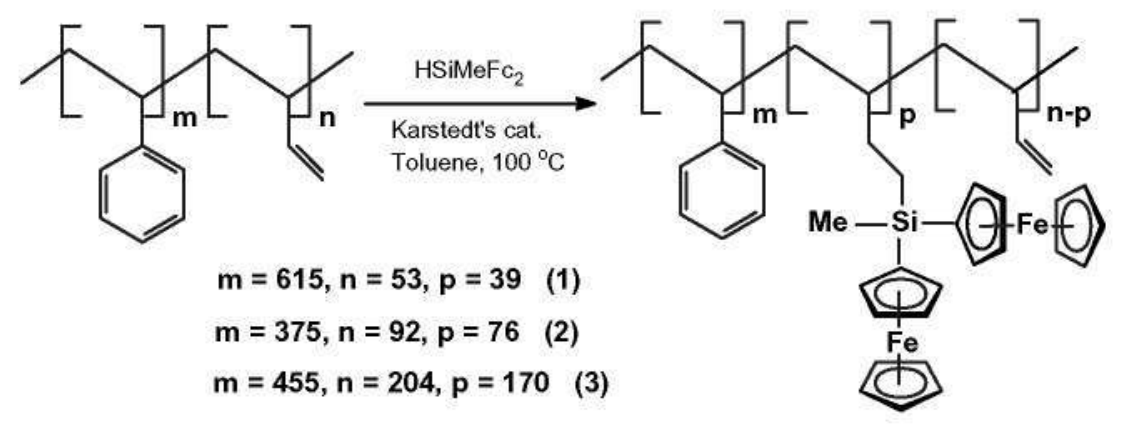

Scheme 1.

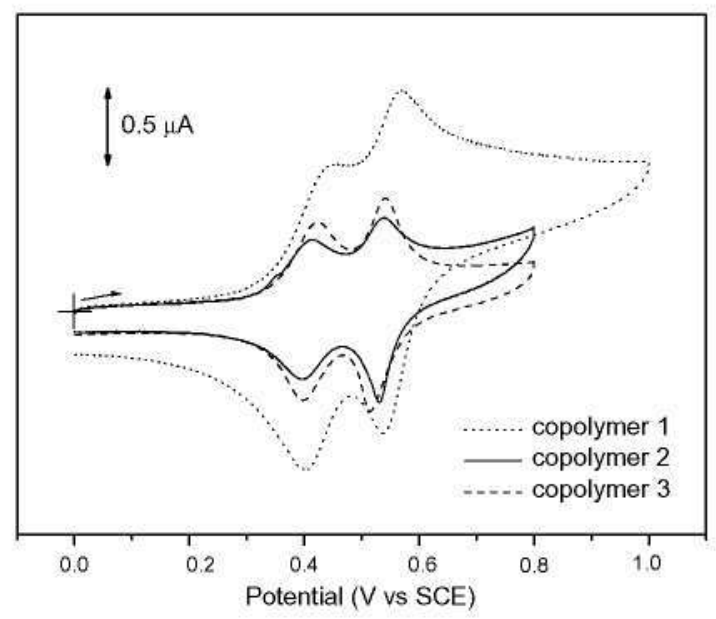

Fig. 1. Cyclic voltammograms of block-copolymers 1,2 and 3 solutions $\left(10^{-4} \mathrm{M}\right.$ approx. in ferrocene centers) in $\mathrm{CH}_{2} \mathrm{Cl}_{2}$ with $n$ - $\mathrm{Bu}_{4} \mathrm{NClO}_{4} 0.1 \mathrm{M}$ as supporting electrolyte, measured at a Pt electrode with $100 \mathrm{mV} \mathrm{s}^{-1}$ scan rate.

Table 2

Electrochemical parameters for the block-copolymers

\begin{tabular}{|c|c|c|c|c|}
\hline Compound & $\begin{array}{l}{ }^{1} E_{1 / 2} \\
(\mathrm{~V} \text { vs. SCE })^{\mathrm{a}}\end{array}$ & $\begin{array}{l}{ }^{2} E_{1 / 2} \\
\left(\mathrm{~V} \text { vs. SCE) }{ }^{\mathrm{a}}\right.\end{array}$ & $\begin{array}{l}D_{0} \\
\left(\times 10^{6} \mathrm{~cm}^{2} \mathrm{~s}^{-1}\right)^{\mathrm{b}}\end{array}$ & $\begin{array}{l}k^{0} \\
\left(\mathrm{~cm} \mathrm{~s}^{-1}\right)\end{array}$ \\
\hline 1 & 0.43 & 0.55 & 0.61 & $1.7 \times 10^{-2}$ \\
\hline 2 & 0.40 & 0.53 & 0.52 & $7.4 \times 10^{-3}$ \\
\hline 3 & 0.41 & 0.52 & 0.55 & $3.0 \times 10^{-3}$ \\
\hline
\end{tabular}

a Measured in $\mathrm{CH}_{2} \mathrm{Cl}_{2}$ with $0.1 \mathrm{M}$ TBAP.

b Diffusion coefficients measured by D.L.S.

The architecture of the macromolecular structure to which the ferrocene substituents are attached seems to be essential for the accessibility in terms of electron transfer. The $k^{0}$ values reveal that the kinetics of electron transfer slows down with an increase of both the butadiene content and the block length ratio (PB/PS). This behaviour is related to the formation the coiled conformation of the block-copolymers. The experimental data suggest that the redox units are more shielded by the polymer chain, when the block-copolymer contains larger PB-diferrocenylsilane blocks. This finding is consistent with the ratios of experimental and theoretical peak currents observed in the cyclic voltammograms of copolymers previously reported [30].

\subsection{Electrochemical behaviour of the modified electrodes}

The block-copolymers were deposited onto electrode surfaces either by controlled potential electrolysis at $+0.8 \mathrm{~V}$ (Vs. SCE) or by performing a certain number of consecutive cycles between 0 and $+1.2 \mathrm{~V}$ potential limits. Therefore the amount of electroactive material deposited can be controlled with the electrolysis time or the number of scans.

The microstructures of films of copolymers $\mathbf{2}$ and $\mathbf{3}$, which contain lower amounts of styrene, electrochemically deposited on a platinum wire electrode $(0.25 \mathrm{~mm}$ diameter) were examined by scanning electron microscopy. The SEM micrograph in Fig. 2A shows that the film of polymer $\mathbf{3}$ appears to be a relatively dense,

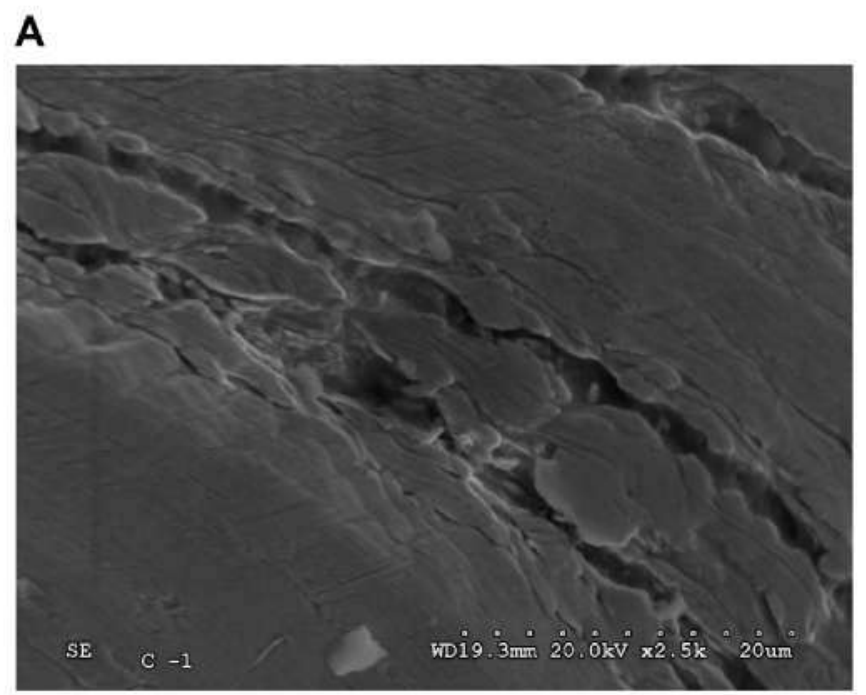

B

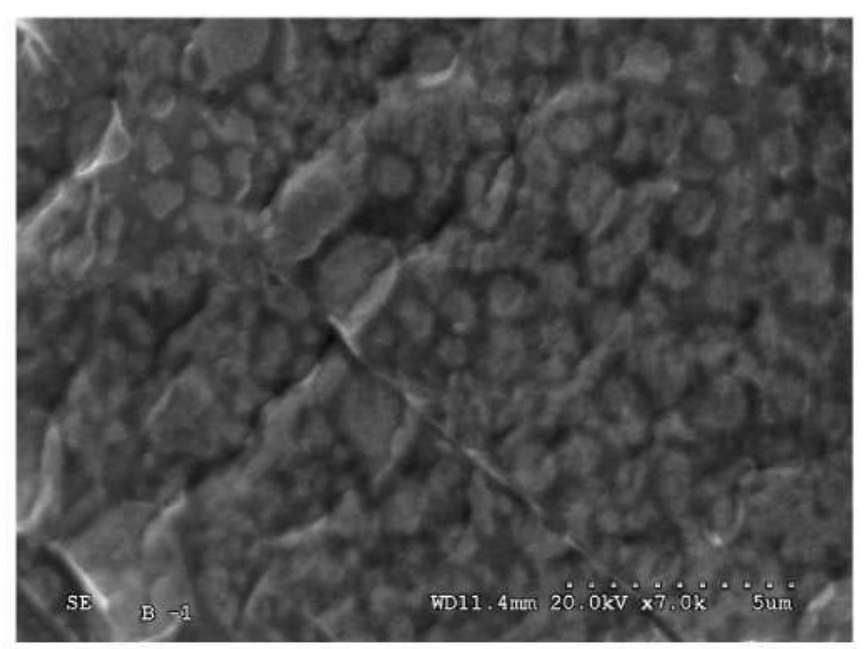

Fig. 2. SEM micrographs of the surface of platinum wire electrodes modified with films of copolymer $\mathbf{3}(\mathrm{A})$ and copolymer $\mathbf{2}$ (B). 
multilayered material with a compact structure. The film formed by electrodeposition of copolymer 2 displays a less compact morphology consisting of randomly packed polymer aggregates (Fig. 2B). It is well known that this kind of polymers tend to phase separate in the bulk, if both blocks are immiscible, giving rise to cylindrical or lamellar domains. However, the influence of this nano-phase segregation was not the focus of our current work.

In non-aqueous $\left(\mathrm{CH}_{2} \mathrm{Cl}_{2}\right)$ solutions, films of the three polymers deposited on platinum give a similar electrochemical response, which is reminiscent of the corresponding compounds in solution. The electrochemical properties of the modified electrodes are highly sensitive to the nature of the solution. As can be seen, in phosphate buffer solution the cyclic voltammograms display the peaks corresponding to the oxidation of the interacting ferrocenyl units practically overlapped with $\mathrm{E}_{\mathrm{pa}}$ values of about $0.45 \mathrm{~V}$ (Fig. 3). The inclusion of polarizable solvent molecules between the ferrocene moieties and the formation of ion pairs with specific electrolyte anions probably counteract the electrochemical interaction and cause the merging of the two redox couples. A similar change in the features of the voltammetric responses caused by the action of polar solvents has been found in the case of poly(dialkylsilyleneferrocenylene) films [37].

As indicated by Fig. 4 the anodic wave of the copolymers films appears at more positive potentials in the first scan than in succeeding scans. This is a break-in effect caused by the hydrophobic properties of the polymers which are initially poorly swollen by solvent and electrolyte. This break-in effect is also observed when modified electrodes are reused after storage in water.

The $\mathrm{CV}$ of an electrode modified with polymer 3 differs from the behaviour displayed by electrodes modified with 1 and 2 . In fact, in this case a much sharper signal is observed. This narrow wave can be attributed to attractive interactions between the electroactive centers within the film. This might be an indication of a special type of order on the electrode leading to a better stabilization of the oxidized polymer [38]. On other hand the features of the cyclovoltammograms of the three polymer-modified electrodes change, when they are stored in distilled water. As can be seen after several days the oxidation wave becomes broader, the $f_{p a}$ values decrease slightly and $\Delta E_{\mathrm{p}}$ values increase before a steady-state response is attained.

\subsection{Catalytic oxidation of NADH at the modified electrodes}

Fig. 5 shows the cyclic voltammograms for $2 \mathrm{mM} \mathrm{NADH}$ in aqueous phosphate buffer and a block-copolymer 3 modified plat-

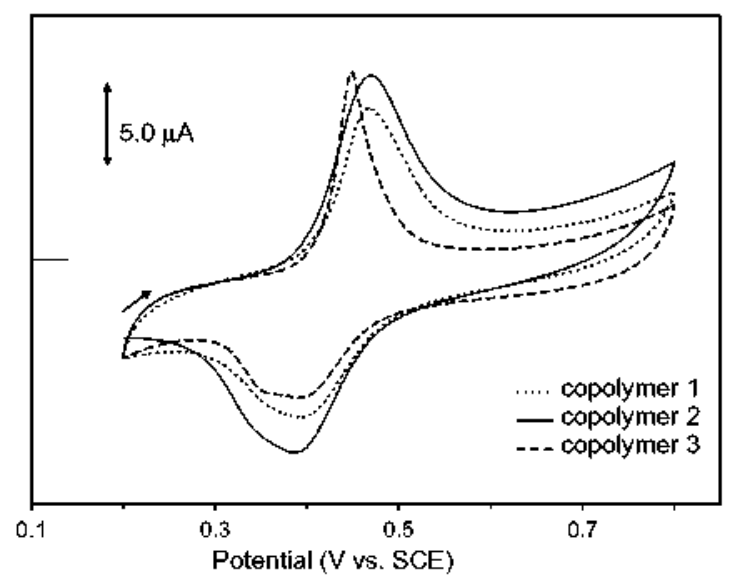

Fig. 3. Cyclic voltanmogiams of copolymers 1, 2 and 3 deposited at platinum electrodes $\left(\Gamma \cong 9 \times 10^{-10} \mathrm{~mol}\right.$ ferrocene $\mathrm{cm}^{-2}$ thickness film) in $0.1 \mathrm{M}$ deaerated phosplate buffer (pH 7.0). Scan late $100 \mathrm{mV} \mathrm{s}^{-1}$.

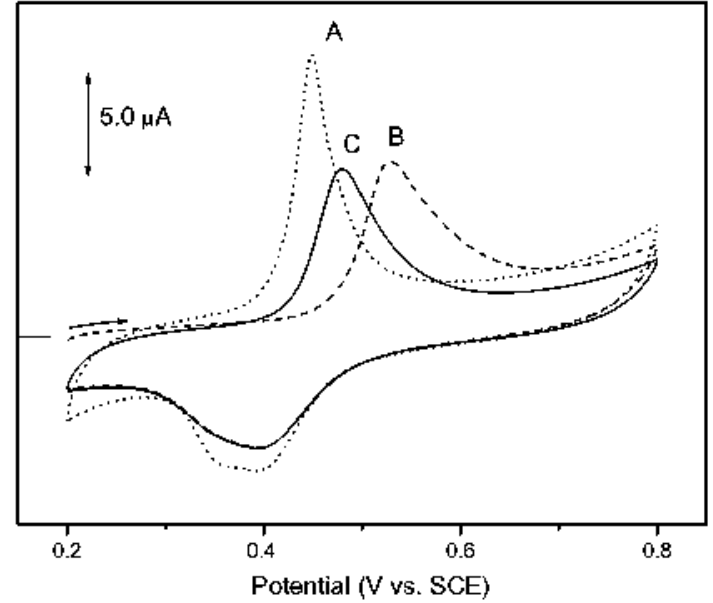

Fig. 4. Cyclic voltanmograms of a $\mathrm{Pt}$ electrode modified with copolymer 3 $\left(\Gamma=9.71 \times 10^{-10} \mathrm{~mol}\right.$ ferrocene $\mathrm{cm}^{-2}$ thickness film) in $0.1 \mathrm{M}$ deaerated phosphate

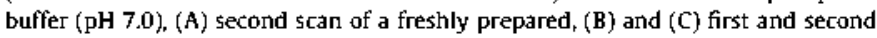
scans respectively, of the same electrode stored in water at room temperature after two months. Scan late $100 \mathrm{mVs}^{-1}$.

inum electrode. A catalytic wave is observed near $0.64 \mathrm{~V}$ hence the modified electrode decreases the overpotential required to oxidize $\mathrm{NADH}$ by $200 \mathrm{mV}$. A similar behaviour is displayed by electrodes modified with 1 and 2.

This catalytic effect is explained by the diffusion of NADH to the electrode where it reduces the oxidized mediator to form $\mathrm{NAD}^{+}$ and the reduced form of the mediator. This reaction is followed by the electrochemical reoxidation of the mediator:

$\mathrm{NADH}+\mathrm{M}_{\mathrm{OX}} \stackrel{k_{1}}{\rightarrow} \mathrm{M}_{\mathrm{RED}}+\mathrm{NAD}^{+}+\mathrm{H}^{+}$
$\mathrm{M}_{\mathrm{RED}}-2 \mathrm{e}^{-} \rightarrow \mathrm{M}_{\mathrm{OX}}$
net : $\mathrm{NADH} \rightarrow \mathrm{NAD}^{+}+\mathrm{H}^{+}+2 \mathrm{e}^{-}$

The rate-determining step is given in Eq. (1) with a second-order rate constant $k_{1}$. Thus the reaction in Eq. (2) can be considered fast compared to that in Eq. (1).

The rate of the chemical reaction between NADH and the surface immobilized mediator $\left(k_{1}\right.$, in $\left.\mathrm{M}^{-1} \mathrm{~s}^{-1}\right)$ can be evaluated by cyclic voltammetry $[39,40]$.

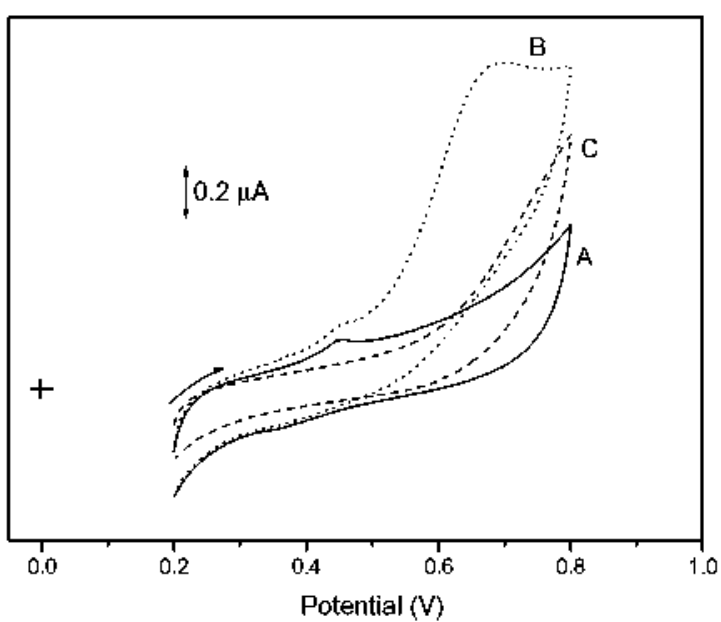

Fig. 5. Cyclic voltammograms of a copolymer $3\left(\Gamma=1.0 \times 10^{-10}\right.$ mol ferrocene $\mathrm{cm}^{-2}$ thickness film) coated platinum electrode in $0.1 \mathrm{M}$ deaerated phosphate buffer $(\mathrm{pH} 7.0$ ) solution in absence $(A)$ and presence (B) of NADH $0.5 \mathrm{mM}$. (C) A platinum bare electrode in presence of NADH $0.5 \mathrm{mM}$. Scan late $5 \mathrm{mV} \mathrm{s}^{-1}$. 
For the simplest case, in which only the mass transport of NADH and/or the rate constant $k_{1}$ can limit the reaction, $E_{\mathrm{p}}$ is [41]:

$E_{\mathrm{p}}=E^{\sigma}+\frac{R T}{n F}\left[0.78+\ln \left(\frac{D_{\text {NADH }}^{1 / 2}}{k_{1} \Gamma}\right)+\ln \left(\frac{n F V}{R T}\right)^{1 / 2}\right]$

the currents of NADH oxidation were increased with the increase of the scan rate and the relationship between current and scan rate is as follows [42]:

$i_{\mathrm{p}}=2.99 \times 10^{5} \mathrm{n}\left(\alpha \mathrm{n}_{\mathrm{a}}\right)^{1 / 2} A C_{0} D_{0}^{1 / 2} v^{1 / 2}$

where $i_{p}, n, \alpha, n_{a}, A, \Gamma, C_{0}, D_{0}, v$ are the peak current in ampere, the number of electrons transferred, the transfer coefficient, the apparent number of electrons involved in the rate-determining step, the electrode area in $\mathrm{cm}^{2}$, the surface coverage, the bulk concentration in mol/ $\mathrm{cm}^{3}$, the diffusion coefficient in $\mathrm{cm}^{2} / \mathrm{s}$ and the scan rate in $V / s$, respectively. In all cases the currents of NADH oxidation measured with electrodes modified with the three copolymers, increased with the increase of the scan rate, and the $i_{p}-v^{1 / 2}$ plots show linearity and demonstrate that the electrocatalytic oxidation is diffusion controlled.

The well known relationship between oxidation potential $E_{p}$ and the peak current $i_{\mathrm{p}}$ is

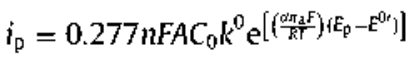

where $E^{0}$ is the formal potential and $k^{0}$ the exchange heterogeneous rate constant in $\mathrm{cm} \mathrm{s}^{-1}[43,44]$.

The values $\alpha n_{a}, n$, and $k^{1}$ (obtained as $k^{0} \Gamma^{-1}$ ) can easily determined from Eqs. (5) and (6). $\alpha n_{a}$ and $k^{0}$ are estimated respectively from the slope and the intercept of the graphs $L_{n} i_{p} v s$. $E_{p}$. The number of electrons, $n$, is provided by Eq. (5) once the $\alpha n_{a}$ values are known.

On other hand we have applied the model developed by Andrieux and Saveant [39] who derived a relation between the peak current and the concentration for the case when $k_{1}$ is infinitely fast:

$i_{p}=0.496 n F A D_{0}^{1 / 2} v^{1 / 2} C_{0}\left(\frac{n F}{R T}\right)^{1 / 2}$

They found that low values of $k_{1}$ result in lower values of the constant $(0.496)$ and $k_{1}$ can be obtained from the plot provided by these authors of the "constant" variations vs. the logarithm of the "kinetic parameter":

$\log \left[\frac{k_{1} \Gamma}{D_{0}^{1 / 2}\left(\frac{n F v}{R T}\right)^{1 / 2}}\right]$

Table 3 summarizes the electrochemical parameters obtained by both procedures for oxidation of NADH solutions at various $\mathrm{pH}$. These rate constants are close to those previously reported for electrodes modified with other mediators such as 1,2-benzophenoxazine-7-one $\left(8 \times 10^{2} \mathrm{M}^{-1} \mathrm{~s}^{-1}\right), \quad 5$-methylphenazinjum $\left(1.5 \times 10^{3} \mathrm{M}^{-1} \mathrm{~s}^{-1}\right), 4$-methylcatechol $\left(3.3 \times 10^{3} \mathrm{M}^{-1} \mathrm{~s}^{-1}\right)$ and poly(thionine) $\left(2.1 \times 10^{3} \mathrm{M}^{-1} \mathrm{~s}^{-1}\right)$.

As can be observed in Table 3 the $k_{1}$ values show a slight increase as the $\mathrm{pH}$ of solutions increases. This fact can be explained,

Table 3

Kinetic parameters for NADH electrooxidation

\begin{tabular}{|c|c|c|c|c|c|c|c|}
\hline \multirow[t]{2}{*}{ Compound } & \multirow[t]{2}{*}{$n^{\mathbf{a}}$} & \multicolumn{3}{|c|}{$k_{1} \times 10^{-3} \mathrm{M}^{-1} \mathrm{~s}^{-1 \mathrm{a}}$} & \multicolumn{3}{|c|}{$k_{1} \times 10^{-3} \mathrm{M}^{-1} \mathrm{~s}^{-1 \mathrm{~b}}$} \\
\hline & & $\mathrm{pH} 6.3$ & $\mathrm{pH} 7.0$ & $\mathrm{pH} 7.7$ & pH 6.3 & $\mathrm{pH} 7.0$ & $\mathrm{pH} 7.7$ \\
\hline 1 & 2.3 & 1.8 & 2.2 & 2.6 & 1.7 & 2.8 & 2.7 \\
\hline 2 & 2.2 & 3.5 & 3.5 & 3.6 & 2.7 & 3.7 & 3.9 \\
\hline 3 & 1.8 & 3.8 & 4.0 & 72 & 6.1 & 4.5 & 9.8 \\
\hline
\end{tabular}

Abtained from cyclic voltammetry by Eqs. (5) and (6)

b Determined using the Andrieux-Saveant's relation. since in the present case the mediator is a two-electron non-proton acceptor type and therefore the proton must be transferred to the contacting solution supporting material.

In general the $k_{1}$ values found for the electrocatalytic oxidation of NADH by the electrodes modified with the three different blockcopolymers increase in the order polymer $1<$ polymer $2<$ polymer 3. that parallels with the presence in the compound of larger ferrocenyl blocks. This behaviour can be attributed to the higher concentration of organometallic centers in $\mathbf{2}$ and $\mathbf{3}$, which allows a more efficient charge transport in their films. Furthermore, this effect seems to prevail over other morphologic and structural effects because the interaction enzyme-electroactive sites should be easier into polymer 2 film than that expected for polymer 3, according to the less compact morphology and more permeable structure of the electrodeposited layers of $\mathbf{2}$.

On the other hand, it can be observed from Fig. 5 that the catalytic wave is not coincident with that of the mediator oxjdation itself. As described previously [45] this can be due to the formation of a charge-transfer complex and the catalytic peak actually represents oxidation of the complex. The catalytic reaction process can be represented as

$\mathrm{NADH}+\mathrm{M}_{\mathrm{OX}} \leftrightarrow\left[\mathrm{NADH}-\mathrm{M}_{\mathrm{OX}}\right] \rightarrow \mathrm{NAD}^{+}+\mathrm{H}^{+}+\mathrm{M}_{\mathrm{RED}}$

The oxidized mediator and NADH combine to form the chargetransfer complex, then the complex decomposes and NADH is oxidized to $\mathrm{NAD}^{+}$and $\mathrm{M}_{\mathrm{RED}}$ is reoxidized at positive potentials.

This mechanism is confirmed by rotating-disk experiments. In the present case, the catalytic process was studied with an electrode modified with a copolymer 1 film (Fig. 6). ${ }^{1}$ The rotating-disk electrode was kept at $0.85 \mathrm{~V}$, within the potential range of the plateau obtained in the voltammetric curve at a low scan rate. Levich plots ( $i$ vs. $\omega^{1 / 2}$ ) reveal kinetic restrictions and the rate constants $k_{1}$ can be evaluated from the intercept of Koutecky-Levich plots $\left(i^{-1}\right.$ vs. $\omega^{-1 / 2}$ ) and are found to be $2.7 \times 10^{3} \mathrm{M}^{-1} \mathrm{~s}^{-1}, 2.9 \times 10^{3}$ $\mathrm{M}^{-1} \mathrm{~s}^{-1}$ and $3.0 \times 10^{3} \mathrm{M}^{-1} \mathrm{~s}^{-1}$ for NADH concentration 2,3 , and $4 \mathrm{mM}$ respectively. At all instances the calculated value of the number of electrons is close to 2 . As can be seen the values of $k_{1}$ are dependent of [NADH]. This fact has been observed for other mediator modified electrodes [43] and has been explained because the formation of a charge-transfer complex takes place in the catalytic oxidation of NADH.

Fig. 7 shows the dependence of anodic current for a copolymer 1 platinum modified electrode on NADH concentration at $500 \mathrm{mV}$ applied potential. The sensor shows a sensitivity of $0.68 \mu \mathrm{A} / \mathrm{mM}$ and a detection limit of $16 \mu \mathrm{M}(S / N=3)$. It is seen that no linear dependence of the anodic current on coenzyme concentration is obtained. This behaviour is in agreement with a two-step electrocatalytic process that may be assumed to proceed, including the formation of a transient complex between NADH and the mediator $[46,47]$.

\subsection{Catalytic oxidation of glucose oxidase at the modified electrodes}

The electrocatalytic application of these copolymers as mediators of glucose oxidase in the glucose oxidation has been also investigated. First of all the behaviour of the copolymers modified electrodes has been studied with GOX in solution. Fig. 8 shows the cyclic voltammogram of a copolymer 1 modified electrode in phosphate buffer at pH 7 containing $5 \mathrm{mg} \mathrm{GOx}$. As it can be seen, in the presence of glucose a striking change in the cyclic voltammogram

\footnotetext{
1 Data with poor reproducibility were obtained with copolymers 2 and 3 Electrodes modified with these copolymers showed a great sensitivity to the application of high rotational speeds, probably due to the increase of the ionic concentration into the films, which affects the films conductivity.
} 

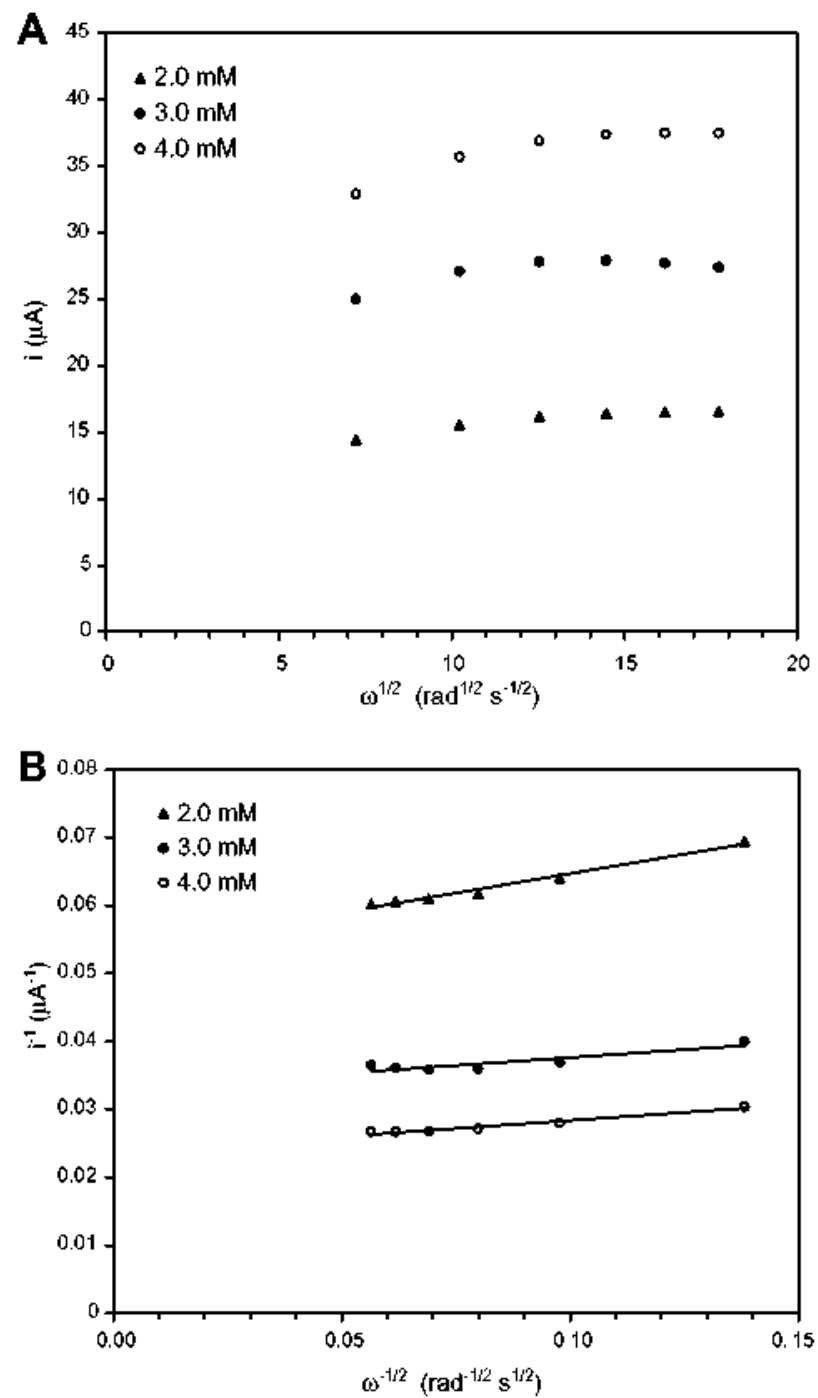

Fig. 6. (A) Levich and (B) Koutecky-Levich plots for the steady electrocatalytic response for a copolymer 1 modified platinum electrode $\left(\Gamma=2.59 \times 10^{-10} \mathrm{~mol}\right.$ ferrocene $\mathrm{cm}^{-2}$ thickness film) at different $\mathrm{NADH}$ concentrations in $0.1 \mathrm{M}$ deaerated phosphate buffer ( $\mathrm{pH} 7.7$ ).

is observed and a remarkable enhancement of the oxidation peak is observed.

The reaction steps required to oxidize glucose and produce electrical current may be written as follows:

Glucose $+\mathrm{GOx}_{(\mathrm{OX})} \rightarrow$ Gluconolactone $+\mathrm{GOx}_{(\mathrm{RED})}$

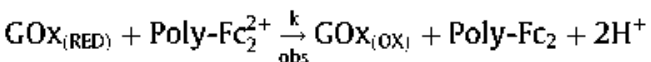

Poly- $\mathrm{Fc}_{2} \leftrightarrow$ Poly- $^{2+} \mathrm{C}_{2}^{2+}+2 \mathrm{e}^{-}$

The rate constant $k_{\text {obs }}$ for reaction (11) can be derived from cyclic voltammetry measurements provided that the electron transfer from the reduced mediator to the electrode (12) is fast compared with the rate of the reaction between ferricinium ion and glucose oxidase, which takes place at the surface films, and there is a sufficient excess of substrate to ensure that the enzyme is fully reduced and the concentration of $\mathrm{GOx}_{\text {(red) }}$ will effectively remain unchanged throughout the experiment.

The observed constant ( $k_{\text {obs }}$ ) values determined from Eqs. (5) and (6) for electrodes modified with the copolymers 1-3 in glucose $50 \mathrm{mM}, \mathrm{GOX} 1.3 \times 10^{-5} \mathrm{M}$, phosphate buffer $\mathrm{pH} 7.0$ solution were

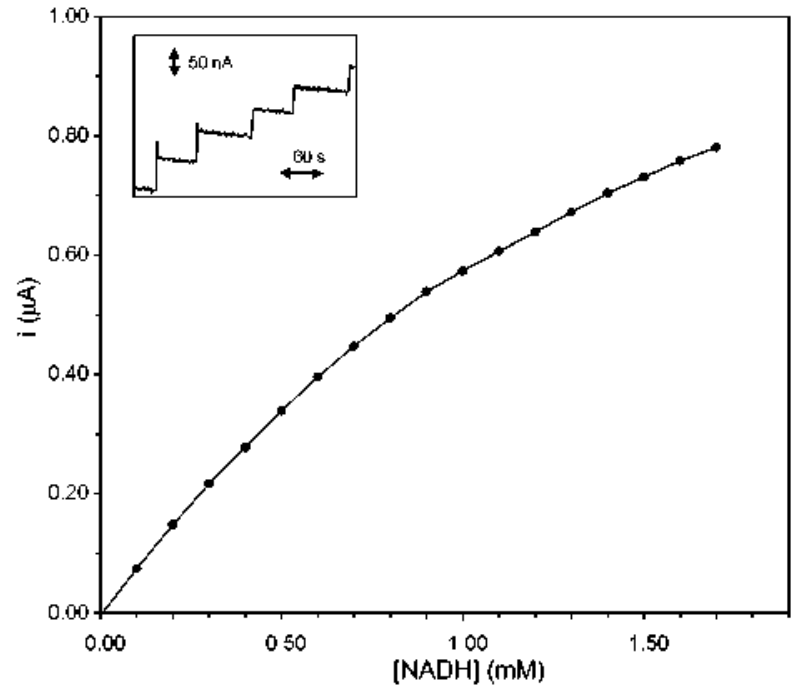

Fig. 7. Calibration curve for NADH oxidation at copolymer 1 modified platinum electrode $\left(\Gamma=9.7 \times 10^{-10} \mathrm{~mol}\right.$ ferrocene $\mathrm{cm}^{-2}$ thickness film) in $0.1 \mathrm{M}$ deaerated phosphate buffer ( $\mathrm{pH} 7.0$ ), $\mathbf{E}=\mathbf{0 . 5} \mathrm{V}$ vs. $5 \mathrm{CE}$. Inset: typical current responses of the modified electrode to consecutive addition of $0.1 \mathrm{mM} \mathrm{NADH}$ aliquots. Each value is the mean result of five electrodes.

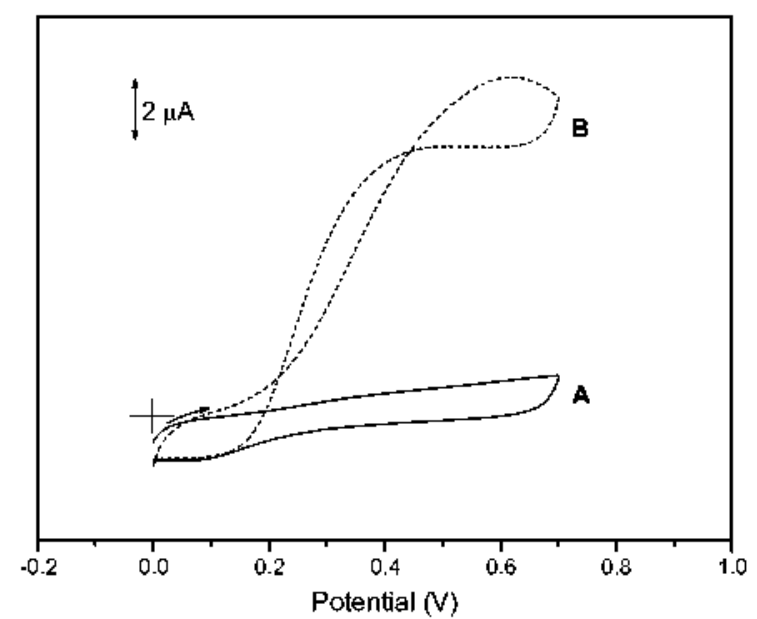

Fig. 8. Cyclic voltammograms of a copolymer $1\left(\Gamma=9.69 \times 10^{-10} \mathrm{~mol}\right.$ ferrocene $\mathrm{cm}^{-2}$ thickness film) coated platinum electrode in deaerated $10 \mathrm{mM}$ glucose solution in $0.1 \mathrm{M}$ phosphate buffer ( $\mathrm{pH} 7.0$ ) solution in absence (A) and presence (B) of $5 \mathrm{mg} \mathrm{GOX} .5 \mathrm{can}$ rate $5 \mathrm{mV} \mathrm{s}^{-1}$.

$4.7 \times 10^{2} \mathrm{M}^{-1} \mathrm{~s}^{-1}, 6.6 \times 10^{2} \mathrm{M}^{-1} \mathrm{~s}^{-1}$ and $4.9 \times 10^{2} \mathrm{M}^{-1} \mathrm{~s}^{-1}$ for the electrodes modified with 1,2 and 3 respectively.

The experimentally derived ratio of anodic current in the presence of enzyme $\left(i_{k}\right)$ to the peak current in its absence $\left(i_{d}\right)$ at a given scan rate may be taken as a measure of the catalytic efficiency of the modified electrodes [39]. For scan rate of $10 \mathrm{mV} \mathrm{s}^{-1}$ and films of the block-copolymers (surface coverage $\Gamma \cong 3.5 \times 10^{-10}$ mol cm${ }^{-2}$ ) the $i_{k} / i_{d}$ values for 1,2 and 3 are $2.3,2.7$ and 3.0 respectively.

\subsection{Glucose sensor properties}

As a representative example the block-copolymer 2 has been evaluated as constituent of amperometric biosensors for D-Glucose. Glucose oxidase was immobilized into conducting films of the polymer by electrostatic interactions, employing the procedure described in Section 2. 


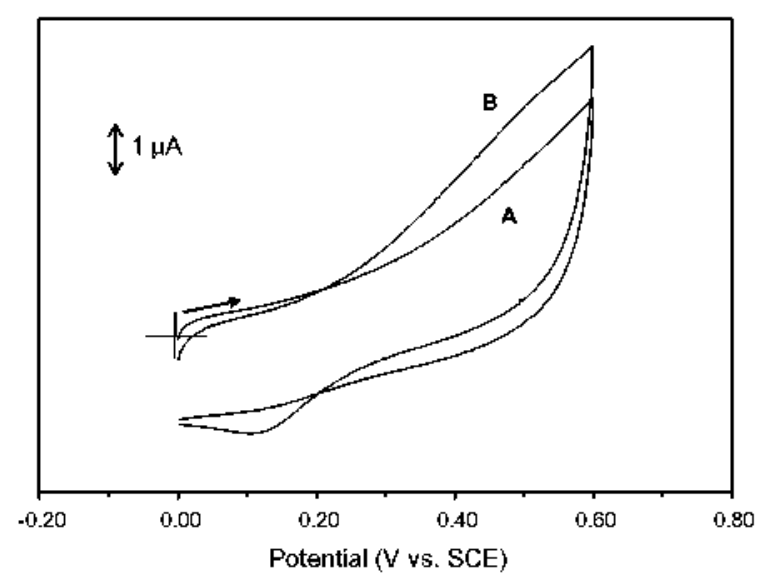

Fig. 9. Cyclic voltammograms of a platimum disk electrode modified with a film of copolymer $2-G 0 \times\left(\Gamma=8.8 \times 10^{-10}\right.$ mol ferrocene per $\mathrm{cm}^{-2}$ thickness film) in $0.1 \mathrm{M}$ deaerated phosphate buffer ( $\mathrm{pH} 7.0$ ) in absence (A) and presence (B) of glucose $5 \mathrm{mM}$. Scan rate $5 \mathrm{mV} \mathrm{s}^{-1}$.

In all cases, the optimal operational conditions in the immobilization process were employed. Immersion periods longer than $30 \mathrm{~min}$ or/and GOx concentrations higher than $0.1 \%$ did not give rise to variations in the results. Fig. 9 shows cyclic voltammograms of a polymer-GOx modified electrode taken in phosphate buffer (pH 7) before (curve A) and after (curve B) $5 \mathrm{mM}$ of glucose were added to the solution. It should be appreciated that the redox peaks in Fig. 9A are not as prominent and intense as those of a polymer-modified electrode (without $\mathrm{GOX}$ immobilization, Fig. 3). The change in the shape of the cyclic voltammogram is usually observed and has been attributed to the effects of the GOX molecules $\left(\mathrm{GOx}^{i n-}\right)$, incorporated by electrostatic interactions in the film structure, on the charge-transfer process. A similar electrochemical behaviour due to the counteranion effects has been previously reported for electrodes modified with films of polymers containing ferrocene units $[16,48,49]$. As can be observed in Fig. 9 the electrochemical behaviour of the enzyme electrodes is influenced by the presence of glucose in solution. When glucose was dissolved in the electrolyte solution, a remarkable increase in the oxidation current was observed at potentials more positive than $0.25 \mathrm{~V}$ vs. SCE, indicating that ferrocene molecules immobilized in the film are efficient electron mediators between the electrode substrate and the redox centers of FAD/GOx. In the presence of glucose the anodic wave increases, which is indicative of an enzymecatalyzed process. In order to test the analytical performance of the enzyme electrodes calibration curves were obtained. Fig. 10 shows the steady-state currents for an electrode modified with copolymer 2 obtained at $0.3 \mathrm{~V}$ as a function of the glucose concentration for electrolyte solutions saturated with $\mathrm{N}_{2}$. The biosensor responds quickly to the substrate additions with a good linear response region even at $300 \mathrm{mV}$ (vs. SCE) working potential. A detection limit of $0.2 \mathrm{mM}(S / \mathrm{N}=3)$ and a sensitivity of $50 \mathrm{nA} / \mathrm{mM}$ were obtained.

In agreement with the model developed by Savinell and coworkers [49], a non-linear lineweaver-Burke plot $\left(i^{-1}\right.$ vs. substrate $\left.{ }^{-1}\right)$ is qualitatively indicative of a mass transport limitation, and that the operating potential suffices to eliminate the electrolysis rate from consideration, this behaviour corresponds to a sensor in which the substrate diffusion becomes slower than other reaction steps [50].

In this kind of sensors, the slope of the calibration curves has a different significance that in the case of processes controlled by the rate of catalysis, because it is independent of the Michaelis-Menten constant [51] but dependent upon the diffusion coefficient of the substrate. If the film thickness is increased, the slope of the calibration plot decreases.

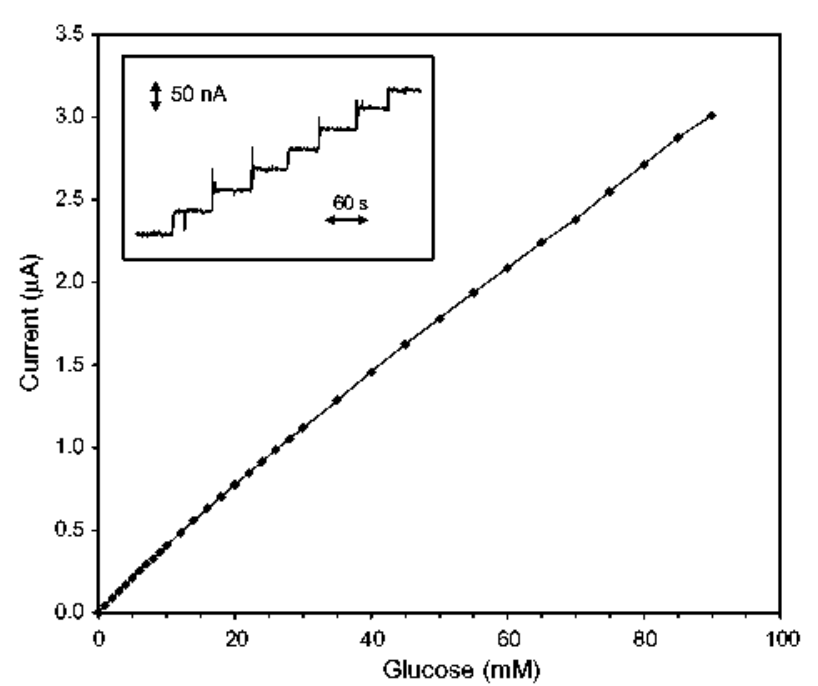

Fig. 10. Glucose calibration plot of copolymer 2 - enzyme sensor $\left(\Gamma=8.8 \times 10^{-10} \mathrm{~mol}\right.$ ferrocene $\mathrm{cm}^{-2}$ thickness films). Steady-state currents measured at +0.30 V (vs. SCE), in $0.1 \mathrm{M}$ deaerated phosphate buffer ( $\mathrm{pH} 7.0$ ). Each value is the mean result of five electrodes. Inset: typical current responses of the sensor to consecutive addition of $1 \mathrm{mM}$ glucose aliquots.

When the rate of the enzymatic reaction is mass transport controlled, a value for Michaelis-Menten constant may be calculated from the slope of the Lineweaver-Burke plot by extrapolation [51] but in fact, it is an "effective" or "apparent" constant $K_{\text {M.app. }}$ due to the diffusion limited process. The $K_{M, a p p}$ determined from L-B plots at an operating potential of $0.30 \mathrm{~V}$ was 72.7 . This value of $K_{\mathrm{M} \text {,app }}$ obtained is larger than the intrinsic value and the linearly measurable range is greatly enhanced. In fact, it has been reported previously that the linear range of glucose sensors can be increased substantially by using an additional polymer coating on the surface of the sensor [52,53]. In the same way, the copolymer probably provides an intrinsic resistance to the diffusion of glucose, due to the compact structure of the films.

The equivalent Michaelis constant obtained is lower than other reported constants for sensors based on similar ferrocene dendrimers and polymers [54,55]. This finding indicates that these block-copolymers with interacting ferrocenes are more efficient redox enzymatic mediators.

\section{Conclusions}

The electrochemical properties of a series of block-copolymers functionalized with interacting di(ferrocenyl)silanes have been examined. It has been found that the electrochemical behaviour of these polymers is affected by structural characteristics. As it was expected, the presence of polystyrene blocks confers longterm stability and reproducibility to the electrodes modified with block-copolymer films, which we attribute to the excellent filmforming properties of the polystyrene blocks. The results confirm that electrodes modified with the examined copolymers are efficient redox mediators for the electrocatalytic oxidation of both reduced nicotinamide dinucleotide cofactor and glucose oxidase. The reaction with NADH proceeds via formation of a charge-transfer intermediate before yielding the reaction products.

The rate constants are significantly higher than those previously found for electrodes modified with monomeric ferrocenes and comparable with the values reported for several different immobilized mediators. This is a novel example of electrodes modified with ferrocene derivatives that can be applied to the determination of NADH without the use of diaphorase. 
The redox copolymers co-immobilized with glucose oxidase have also been successfully used as amperometric biosensors for glucose determinations. As expected these compounds allow using lower working potentials $(0.25 \mathrm{~V}$ vs. SCE) that contributes to reduce the effect of the interfering electrochemical compounds. The sensitivities and detection limits obtained are comparable or even better than those of other ferrocene-modified polymer-mediator based electrodes. Further detailed work on the influence of the macromolecular architecture on the electrochemical properties of block- and random copolymers of the type introduced here is in progress.

\section{Acknowledgements}

The authors thank the Spanish Dirección General de Investigación (Projects No. CTQ2004-07381-C02-02 and 01) and Consejería de Educación, Comunidad de Madrìd (S-0505/PPQ-0328) for financial support of this research.

\section{References}

11 A. Togni, T. Hayashi (Eds.), Ferrocenes. Homogeneous Catalysis, Organic Synthesis, Materials Science, VCH, Weinheim, 1995.

|2| P. Nguyen, P. Lopez-Elipe, I. Manners, Chem. Rev, 99 (1999) 1515.

[3] G.R. Whittell, I. Manners, Adv, Mater. 19 (2007) 3439.

[4] l. Manners, in: I. Manners (Ed.), Synthetic Metal-Containing Polymers, WileyVCH, Weinheim, 2004, p. 237.

[5] P.A. Chase, R.J.M.K. Gebbink, G. van Koten, J. Organomet. Chem. 689(2004) 4016

|6| D. Astruc, in: A.S.A. Abd-El-Aziz, I. Manner's (Eds.). Frontiers in Transition Metal-Containing Polymers, Wiley. Hoboken, NJ, 2007 (Chapter 11).

[7] S. Förster, T. Plantenberg, Angew. Chem. 41 (2002) 689.

|8| J. Rodríguez-Hernăndez. F. Clécot, Y. Gnanou, S. Lecommandoux, Prog. Polym. Sci. $30(2005) 691$.

|이 N. Hadjichristidis, S. Pispas, G. Floudas, Block Copolymers: Synthetic Strategies, Physical Properties, and Applications, Wiley-Interscience, NJ. 2003.

[10] D.G. Bucknall, H.L. Anderson, Science 302 (2003) 1904.

[1] O. Nuyken, V. Burkhardt, C. Hubsch, Macromol. Chem. Phys. 198 (1997) 3353.

[12] M. Baumert, J. Fröhlich, M. Stieger, H. Frey, R. Mülhaupt, H. Plenio, Macromol. Rapid Commun. 20 (1999) 203.

[13] D.A. Durkee, H.B. Eitouni, E.D. Gomez, M.W. Ellsworth, A.T, Bell, N.P. Balsal'a, Adv. Mater. 17 (2005) 2003.

[14] I. Manners, Angew. Chem, 46 (2007) 1565.

[15] B. Alonso, C.M. Casado, l. Cuadrado, M. Moran, A.E. Kaifer, Chem. Commun. (2002) 1778 .

[16] M.P. García Armada, J. Losada, ]. Cuadrado, B. Alonso, B. González, E. RamírezOliva, C.M. Casado, Sensor. Actuat. B-Chem. 88 (2003) 190.

[17] M.P. García Armada, J. Losada, ]. Cuadrado, B. Alonso, B. González, C.M. Casado. J. Zhang, Sensor. Actuat. B-Chem. 101 (2004) 143.
|18| F. le Floch, H.A. Ho. P. Harding-Lepage, M. Bedard, R. Neagu-Plesu, M. Leclerc, Adv. Mater. 17 (2005) 1251.

|19| J.M. Gibbs, 5.J. Park, D.R. Anderson, K.J. Watson, C.A. Mirkin, 5.T. Nguyen, J. Am. Chem. Soc. 127 (2005) 1170 .

[20] C. Ueda, DC-S. Tse, T. Kuwana, Anal, Chem. 54 (1982) 850.

121] A. Tor'stensson, L. Gorton, J. Electroanal. Chem. 130 (1981) 199.

[22] B.W. Carlsson, L. Miller, J. Am. Chem. Soc. 106 (1983) 3850.

|23| M.J. Lobo, A.J. Miranda, J.M. López-Fonseca, P. Tuñon, Anal. Chim. Acta 325 (1996) 33.

|24| D. Narasaial, U. Spoln, L. Gorton, Enzyme Eng. Xll 799 (1996) 482.

|25| L. Gorton, B. Persson, P.D. Hale, L.]. Boguslavsly, H.I. Karan, H.S, lee, T.A. Skotheim, H.L Lan, Y. Okamoto, in: P.G. Edelman, J. Wang (Eds.), Biosensors and Chemical Sensors, ACS Symposium Series, Am. Chem. Soc. 487 (1992) 56.

[26] M.V. Pishko, A.C. Michael, A. Heller, Anal. Chem. 63 (1991) 2268.

|27| N.C. Foulds, C.R. Lowe, Anal. Chem. 60 (1988) 2473

[28| P.D. Hale, L.]. Boguslavsky, H. Inagaki, H.I. Karan, H.S, lee, T.A. Skotheim, Y, Okamoto, Anal. Chem. 63 (1991) 677.

|29| J. Losada, M.P. Garcia Armada, I. Cuadrado, B. Alonso, B. Gonzalez, C.M. Casado, J. Zhang, J. Organomet. Chem. 689 (2004) 2799.

[30] A.G. Marcos, T.M. Pusel, R. Thomann, T. Pakula, L. Okrasa, S. Geppert, W. Gronski. H. Frey, Macromolecules 39 (2006) 971.

[31] F.]. López-Villanueva, A. García Marcos, K. Fischer, M. Schmidt, B. Alonso, C.M. Casado. M.P. García Armada, J. Losada, H. Frey, Am. Cliem. Soc, 47 (2006) 1087

[32] F.j. López-Villanueva, H. Schüle, A. García Marcos, B. de Juan, K. Fischer, M. Schmidt, B. Alonso, C.M. Casado, M.P. García Amada, J. Losada, H. Frey, in preparation.

[33] B. Alonso, B. González, B. García, E. Ramírez-oliva, M. Zamora, C.M. Casado, l. Cuadrado. J. Organomet. Chem. 637 (2001) 642.

[34| R.S. Nicholson. Anal. Chem, 37 (1965) 1351.

[35] M.V. Milkin, A.J. Bard, Anal. Chem. 64 (1992) 2293.

|36| A.E. Kaifer, C.M. Cardona, J. Am. Chem. Soc. 120 (1998) 4023.

[37] H.T. Nguyen, A.F. Diaz, V. Dementev, K.H. Pannell, Chem. Mater. 6 (1994) 952.

[38| H.D. Abruìa, Coord. Chem. Rev, 86 (1988) 135.

[39] C.P. Andrieux, J.M. Saveant, J. Electroanal. Chem. 93 (1978) 13.

[40] H. Jaegfeldt, T. Kuwana, G. Johansson, J. Am. Chem. Soc. 105 (1983) 1805.

141| L. Gorton, J. Chem. Soc., Faraday Trans. 82 (1986) 1245.

[42] A.J. Bard, I.R. Faulkner, Electrochemical Methods, Wiley, New York, 1980.

|43| F.D. Munteanu, L.T. Kubota, L. Gorton, J. Electroanal. Chem. 509 (2001) 2.

[44] J. González Velasco, Electroanalysis 9 (1997) 880.

[45] Q. Chi, S. Dong, Analyst 119 (1994) 1063.

|46| A. Malinauskas, T. Ruzgas, L. Gorton, J. Colloid. Jnterf. Sci. 224 (2000) 35

[47] M.J. Lobo, A.]. Miranda, P. Tuñon, Electroanalysis 9 (1997) 191.

|48| G. Jnzelt, Ln Szabo. Electrochim. Acta 31 (1986) 1381.

149| Ch.J. Chen, Ch. liu, R.F. Savinell, J. Electroanal. Chem, 348 (1993) 317.

[50] R.A. Kamin, G.S. Wilson, Anal. Chem. 52 (1980) 1198.

[51) L.D. Mell, J.T. Maloy. Allal. Chem. 47 (1975) 299.

[52] L. Boguslavsky, H. Kalash, Z. Xu, D. Beckles, L. Geng, T. Skotheim, V. Laurinavicius, H.S. Lee, Anal. Chim. Acta 311 (1995) 15.

|53| L. Gorton, H.I. Karan, P.D. Hale, T. Inagaki, Y. Okamoto. T.A. 5kotheim, Anal. Chim. Acta 228 (1990) 23.

|54| B. Alonso, M.P. García Almada, J. Losada, J. Cuadrado, B. González, C.M. Casado Biosens. Bioelectron. 19 (2004) 1617.

[55] J. Losada, M.P. García Amada, I. Cuadrado, B. Alonso, B. González, C.M. Casado, J. Zhang. J. Organomet. Chem. 689 (2004) 2799. 